\title{
ELEMENTS OF ENVIRONMENTAL MANAGEMENT \\ SYSTEMS ACCORDING TO ISO 14001 RELEVANT FROM THE POINT OF VIEW \\ OF AN INSURANCE COMPANY - THE RESULTS OF EMPIRICAL RESEARCH
}

The following paper presents the findings of the research concerning environmental insurance and environmental management systems in conformity with ISO 14001, and is a part of a broader research project. It shows the interrelation between the attributes of organisations managed according to ISO 14001 and the implementation therein of RSS (relevant systemic solutions). RSS refer to elements of environmental management systems (EMS) relevant from the point of view of an insurance company which provides environmental insurance. The RSS were divided into four groups of dependent variables (personal integration variables, project variables, informative potential variables and volume of risk variables). The attributes of the organisations managed according to ISO 14001 were catalogued in three sets of independent variables (systemic, organisational and awareness-related features). The research comprised statistical analysis in order to identify the interrelations between the above variables. The analysis has shown that the largest number of correlations was obtained in the area of the informative potential variables and selected scope of volume of risk variables (especially these referring to monitoring of the aspects affecting the volume of insurance risk, taking preventive and repressive actions and planning the response procedures to potential emergency situations). Simultaneously, statistically significant relations were most frequently identified between the above RSS and the awareness-related attributes of organisations. The higher in the respondents' opinion was the likelihood of the damage occurrence, the likelihood and severity of its particular consequences, as well as the impact of both the legal acts and particular regulation categories in environmental area, the more frequently they implemented the systemic solutions essential to provision of insurance cover.

Keywords: environmental insurance, environmental management system ISO 14001, RSS, EMS

JEL Classification: G22, Q50, K21

DOI: $10.15611 /$ aoe.2021.2.12

\footnotetext{
* Department of Insurance, Poznan University of Economics and Business, Poznan, Poland.
} 


\section{INTRODUCTION}

The human impact on the state of the environment has troubled mankind for centuries. However, only the advent of the $20^{\text {th }}$ century, made humans realise the irreversibility of the changes to the elements of the environment and has stimulated the international community to take steps towards environmental protection. In the 50 years since the appeal by $U$ Thant, the then UN General Secretary, which is believed to have given rise to presentday environmentalist thought, we have witnessed a host of declarations, pledges, legislations and numerous initiatives towards the regulation of human activity and its impact on the environment. Such initiatives were multi-faceted and as early as in the 1970s it became clear that all these activities were lacking in coordination. Despite the development of a multitude of instruments for managing environmental risk, they remained unintegrated. Hence even today, their complete potential is left unfulfilled.

This work addressed the possible integration of environmental insurance ${ }^{1}$ and ISO 14001 environmental management systems. Although the opportunities behind the integration of these instruments were noted just after the introduction of the ISO 14001 standard, there have been insurmountable barriers to the proper fulfilment of this relation. The results of this research project, however, should contribute to the future development of a platform for the integration of these instruments. It was assumed that the project will achieve the following objectives:

1) identification of the systemic solutions in organisations (i.e. relevant systemic solutions RSS), that are relevant from the environmental insurer's point of view;

2) assessment of the extent (degree) of the relevant systemic solutions' implementation in organisations with the certified environmental management system ISO 14001 in Poland;

3) description of the dependence between implementation of the relevant systemic solutions and the attributes of a systemically managed organisation;

4) description of the dependence of propensity for implementation of the relevant systemic solutions on the attributes of an environmentally managed organisation;

5) description of the relation between the propensity for the implementation of relevant systemic solutions and the generated factors which motivate such action.

\footnotetext{
${ }^{1}$ The scope of this term assumed in the article, cf. Lemkowska 2020b, pp. 33-35.
} 
The findings referring to the attainment of the objectives 1 and 2 have been separately presented in other publications (Lemkowska 2020a; Lemkowska 2020b). The quantitative analyses aimed at achieving objectives 3 to 5 are discussed below.

\section{LITERATURE REVIEW}

Ever since the publication of the initial version of ISO 14001 standard, the relation between environmental insurance and ISO 14001 environmental management systems has been of interest to the representatives of insurance industry, scientific circles as well as environmental institutions. Due to the lack of empirical data on systems functioning in line with ISO 14001, the analyses in their early stages were focussed on the exploration of systems structure and their connections to the construction of insurance products. In 1998 Swiss Re held a seminar for its clients devoted to ISO 14001, the then newly published standard for environmental management systems. The postconference publication (Environmental..., 1998) discussed the presumed importance of systemic environmental management for providing insurance cover. It was found that systems operating within ISO 14001 can reduce uncertainty regarding the likelihood of occurrence and severity of damage, thereby increasing insurability of environmental risk. At the same time, the decision to implement ISO 14001 EMS was linked to the high expectations of the entities implementing the systems for being offered favourable insurance terms. On the other hand, though, it was emphasized that the value of the ISO 14001 certification was limited in the eyes of most insurers in view of its lacking uniform interpretation, which could only be verified by the potential insured's own due diligence. Moreover, loopholes in accreditation and certification were pointed out, which led to the lower quality of certification services, and in turn lowered the credibility of environmental management systems in accordance with ISO 14001 (Environmental..., 1998).

At the beginning of the $21^{\text {st }}$ century the problem of the relations of environmental insurance and ISO 14001 EMS was subject to analyses by British researchers. A series of workshops and interviews were held among representatives of the insurance sector (insurers, loss adjustors, reinsurers) in order to identify the attitudes within the sector toward the development of environmental management systems. Among other discoveries, the scant interest of the insurance sector was noticed, resulting primarily from their limited activity in the area of environmental risk. At the turn of the centuries, 
the British insurance sector had not recognised any benefits resulting from ISO 14001 EMS implementation in the insured / potentially insured entities. Even though the respondents to the survey intuitively pointed to the advantages of external audits, the systems' informative potential or environmental benefits (Minoli, Bell, 2002a), the degree of development of environmental insurance market, as well as the lack of cohesion in the areas where the two environmental risk management instruments were used (e.g. referring to the impact of past events) resulted in a situation in which insurers neither dwelt upon the importance of EMSs nor motivated their clients to implement them (Minoli, Bell, 2002b). Insurers stressed that while offering elaborate insurance products where environmental risk constituted just a fraction of the insured area, it may be much easier to manage the scope of their liability under the insurance contracts by using technical and insurancerelated tools for limiting liability. The authors concluded that implementation of ISO 14001 EMSs may affect the development of environmental insurance provided that: firstly, insurers must be willing to cover environmental risks and secondly, the EMS must induce reduction of emissions which are the source of the insurer's liability (Minoli, Bell, 2002b). At the same time, according to reinsurers' opinions, EMS may support the process of risk assessment, but they cannot replace it by any means available. This is because implementation is often dictated by the image purposes, whereas risk assessment is for the insurer / reinsurer at the core of the business decisionmaking (underwriting a risk), which requires thoroughness and focussing on the purpose of assessment (Minoli, Bell, 2003).

Minoli and Bell's study is so far the only comprehensive, scientifically elaborated work on the subject of the evaluation of the relation between environmental insurance and voluntary environmental management systems as perceived by insurance sector representatives. In the two decades which followed ${ }^{2}$, the relation was only occasionally mentioned in research studies, such as in pointing to the insurance benefits as a potential (empirically unverified) impact of environmental management systems implementation (Financial..., 2006; Sorooshian et al., 2018; Zutshi and Sohal, 2004; Jovanovic and Janjiz, 2018). Very few empirical analyses identified expectations of the EMS implementing entities for lowering the insurance premium (Hajduk-Stelmachowicz, 2013) and also evaluated itsfactual application (Hajduk and Woźniak, 2006; Matuszak-Flejszman, 2009; Matuszak-Flejszman, 2010, Santos et al., 2016). Hence, although the expectations concerning the lower premium levels were declared by as many as 35\% (Hajduk-Stelmachowicz,

\footnotetext{
${ }^{2}$ Minoli and Bell's study commenced in 1995 (Minoli, Bell, 2002a).
} 
2013) of the respondents, the ultimate number of the surveyed who experienced the reduction did not exceed $13 \%{ }^{3}$.

The weak interdependence between implementation of an environmental management system and setting the insurance premium amount does not mean that analyses of the state of affairs on the environmental insurance market contain no reference to systemic management standards. Their development is indicated in the context of the 2004 directive and article 14, which urges the member states to take steps facilitating the growth of the environmental liability insurance market. The systemic management of environmental risk, which is pursued in the environmental management system in line with ISO 14001 , is mentioned as one of the ways to overcome the barriers to the development of the environmental insurance market (REFIT..., 2016; Environmental..., 2017; Multi-annual..., 2017). The importance of the relation between environmental insurance and EMS is also clearly seen in the regulations of some European states which make it obligatory to sign an environmental insurance contract or its terms conditional upon implementation of EMS in compliance with ISO 14001 (Spanish report..., 2014; Country Profile..., 2009; Financial Provision ..., 2016). The above remarks encouraged taking action to recognise the structure of the studied instruments with a view to strengthening their integration which would further serve the fulfilment of contemporary developmental goals.

\section{RESEARCH PROCEDURE, METHODS, VARIABLES}

The research was conducted in four stages.

The data for the first stage analysis was obtained by means of non-real time, time-extended, text-based online focus group surveys completed via bulletin board. The interview was unstructured and the measurement instrument was a scenario. The transcript of the interview was subject to processing procedures appropriate for qualitative data, with the use of template analysis, supported by narrative approaches (Lemkowska, 2020c).

\footnotetext{
${ }^{3}$ In 2000 no respondent reported a benefit in the form of a lowered premium amount resulting from implementation of EMS (Matuszak-Flejszman, 2000); the situation was similar in 2005 in Podkarpackie Voivodship (Hajduk, Woźniak, 2006); in 2007 in Poland 11.3\% of the respondents indicated premium amount reduction as the consequence of implementing EMS (Matuszak-Flejszman, 2009); in 2009 in Poland 14\% (Matuszak-Flejszman, 2010), in 2013 (research findings publishing date) in Podkarpackie Voivodship in Poland 7\% (Hajduk-Stelmachowicz, 2013); in Portugal, in 2016 (research findings publishing date) for SMEs it was 11.7\% (Santos et al., 2016).
} 
The subsequent stage encompassed the analysis of theoretical (legal and economic) grounds for insurance activities as well as the principles regarding environmental management systems in accordance with ISO 14001.

The findings of the first two stages constituted the basis for the creation of the survey questionnaire. The third phase - an electronic survey - was conducted amongst organisations in Poland which had implemented the environmental management system in conformity with ISO 14001. The data regarding the values of the variables were subject to statistical analysis of variance (phase 4).

The first stage (focus group) was completed between 19 and 28 March 2018 (Lemkowska, 2020c). The purpose here was to identify the systemic solutions implemented in organisations which were relevant from the point of view of the insurer providing cover with regard to environmental risk (RSS). The expert focus group, which comprised insurance specialists active on the Polish market within the area of providing cover for environmental risk, did not address the specific attributes of environmental management systems in conformity with ISO 14001 (i.e. the principles for developing EMS or their components which might be applicable in the process of insurance provision). The respondents did not issue any recommendations either as regards EMS implementation methods in the way which would meet the sector's needs and strengthen market growth, and they focussed solely on the identification of the barriers to application of systemic environmental management in the process of insurance provision, merely pointing to its few useful aspects.

Amongst the useful applications of a systemic approach to environmental management the respondents indicated organisation, structure and systemic tools which theoretically should have a positive influence on environmental risk. The information about EMS implementation in line with ISO 14001 only sporadically matters when it comes to making underwriting decisions. Nevertheless, in many cases of in-depth risk assessment, insurers use system information (i.e. plans for reviewing emissions, nuisance and results of these reviews), but they are usually unaware of the relation between the documents and environmental management systems in accordance with ISO 14001.

The experts were unanimous that implementation itself of environmental management systems in accordance with ISO 14001 cannot be the basis for drawing conclusions about more favourable (from the insurer's point of view) parameters of insurance risk when compared with organisations which have not applied certified environmental management systems in conformity with the ISO 14001 standard. This statement partly explains the weak interest that 
insurers show in the significance of systemic environmental management for the process of providing insurance.

The focus group survey showed the experts as lacking the ability to identify the elements of ISO 14001 EMSs relevant to insurance purposes. The entities in the insurance sector cannot recognise the usefulness of systemic environmental management, they only point to the essential traits of EMSs, without the analysis of their elements such as the organisational context, environmental aspects, environmental aims, effectiveness analysis or, ultimately, systemic documentation. Due to the above - exclusively on the basis of the theoretical analysis of the essentials of insurance activity, preparation and offering insurance cover - an index of dependent variables (an index of relevant systemic solutions) was created. The variables were divided into four categories: personal integration variables, project variables, informative potential variables, volume of risk variables - as described in Table 1.

The relevant systemic solutions (dependent variables) are the elements of environmental management in conformity with ISO 14001 referring to the areas of organisational impact on the environment which are crucial for environmental risk insurance ${ }^{4}$.

The index of independent variables was created on the basis of a hypothesis regarding the identity of the factors which lead to a positive environmental impact (such as reducing harmful emissions, lowering consumption of natural resources) and factors which determine implementation of the relevant systemic solutions. Although the past twenty years of the history of ISO 14001 environmental management systems have seen numerous studies of their functioning in the economic reality, the subject of the relation between the positive environmental impact and the attributes of an organisation managed according to ISO 14001 standards has hardly been analysed. The research to date has mostly focussed on identifying the causes and effects of the systems' implementation, where the effects were categorised as environmental and economic (Matuszak-Flejszman, 2009; Psomas et al., 2011; Prajogo et al, 2012; Živcović et al., 2013; Potoski and Prakash, 2013; Malmborg and MarkHerbert, 2010); indicating the number of system implementations depending on the organisations' attributes: size, business sector, organisation's age etc. (Singh et al., 2014); the state and its characteristics, e.g. restrictiveness of environmental regulations or foreign trade turnover (Prakash and Potoski,

\footnotetext{
${ }^{4}$ I.e. connected with the potential occurrence of various categories of environmental damage; see Table 1.
} 


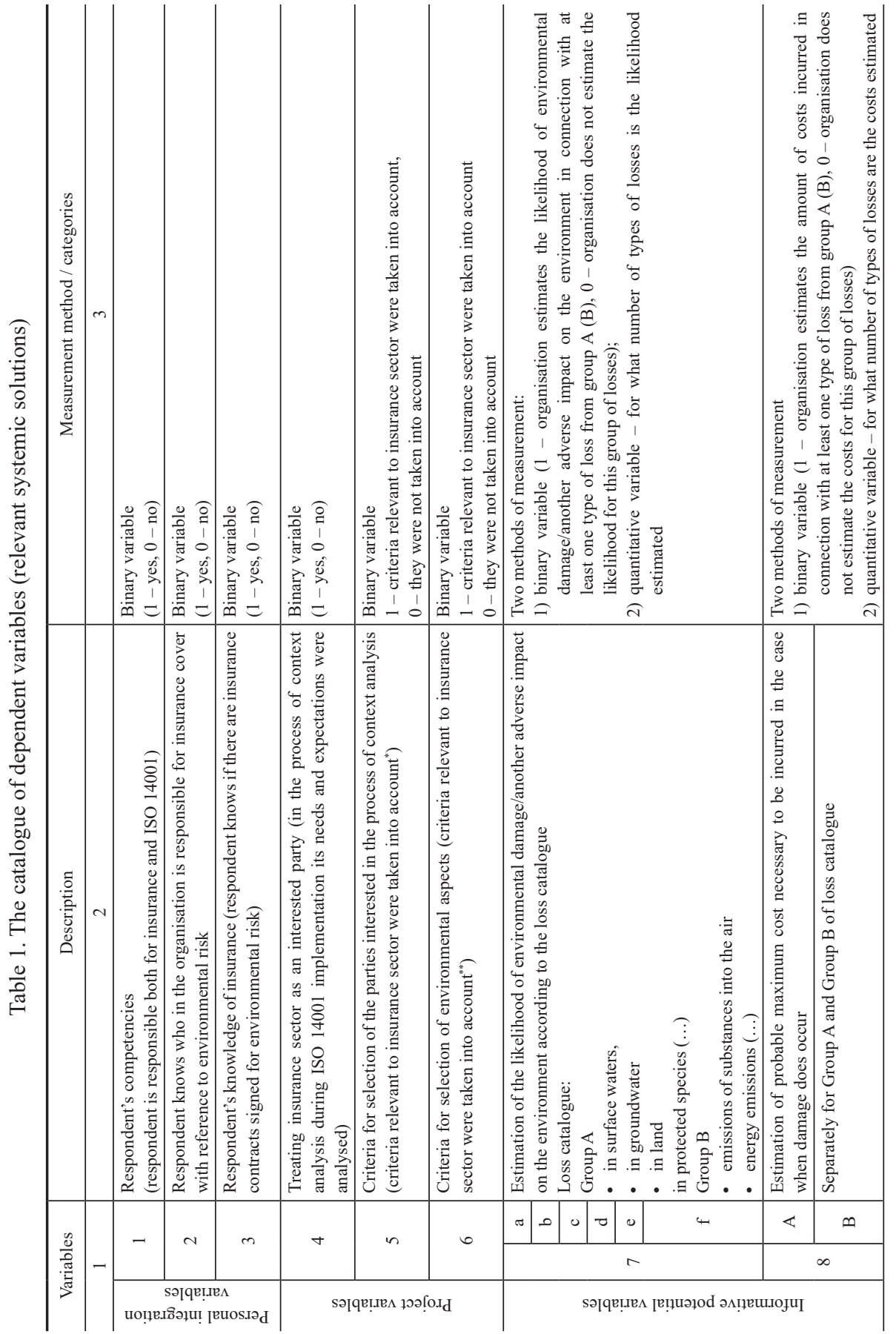




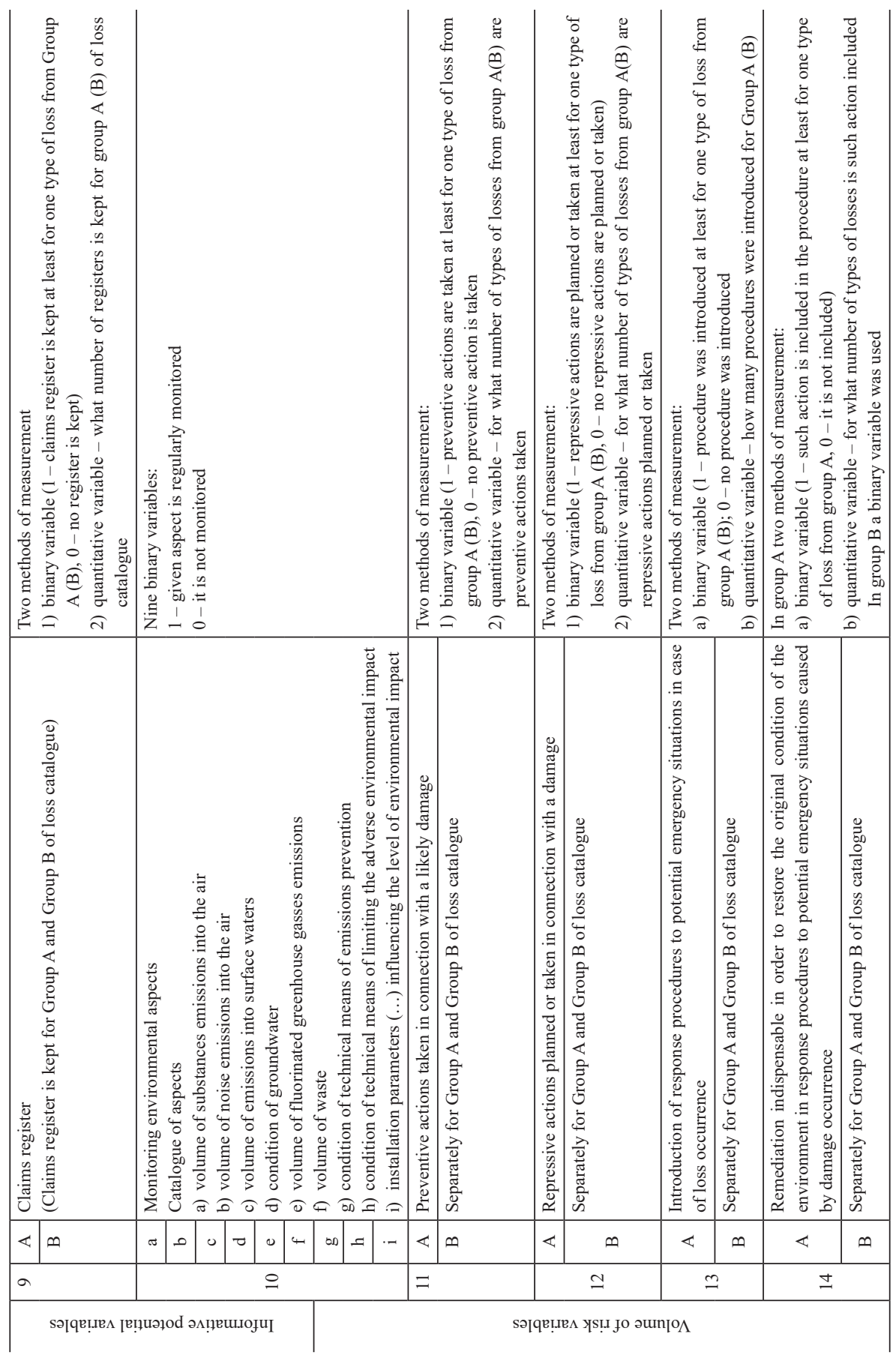



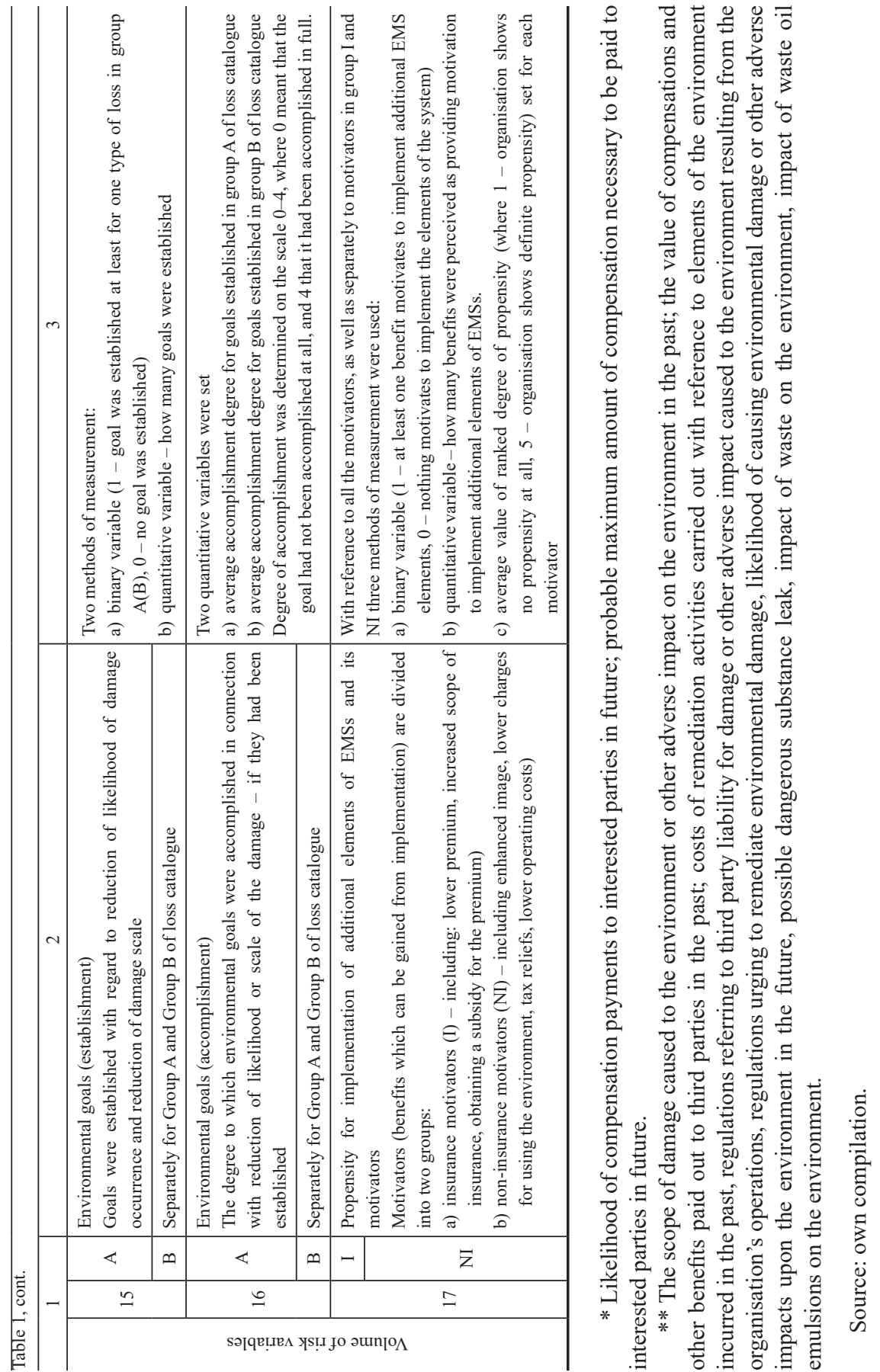
2014; To and Lee, 2014; Berliner and Prakash, 2013; Delmas and Montiel, 2008; Prakash and Potoski, 2007; Massoud et al., 2010); relation between ISO 14001 systems and other environmental management systems as well as systems for management in other areas like quality, safety (Testa et al., 2014; Granly and Welo, 2014; Neugebauer, 2012; Low Sui and Tan, 2005; Heras and Arana, 2010); enhancement of environmental management systems in line with ISO 14001 and its impact on their efficiency and effectiveness (MatuszakFlejszman, 2010); evaluation of environmental audit quality (Prajogo et al., 2016; Heras-Saizabitoria et al., 2013); comparing the outcomes of environmental and financial operations of businesses which have implemented ISO 14001 EMSs and those which have not done it (Zobel, 2013; Naudé et al., 2011; Gomez and Rodriguez, 2011); application of environmental indicators (Comoglio and Botta, 2012); analysis of the human factor significance (commitment of employees, executives, the role of the person responsible for the system) for the efficiency of management in conformity with ISO 14001 (Rodríguezet al., 2011; Perez et al., 2009).

The limited number of studies which concerned the analysis of environmental impact of system implementation were devoted to the assessment of the relation between the above and the attributes such as the size of the organisation, its ownership (private/public), sector (manufacturing/ service), stability/changeability of the applied technologies, amount of time for which the system has been in operation in a given organisation, possession of quality management system in conformity with ISO 9001, or finally, the extrinsic/intrinsic motivation for the system implementation (MatuszakFlejszman, 2010; Prajogo et al., 2012; Boiral and Henri, 2012; Christmann and Taylor, 2006; Fura, 2013; Castka and Prajogo, 2013; Gavronski et al., 2013). Other studies included in the index of environmental efficiency determinants are certain systemic activities/processes/solutions (MatuszakFlejszman, 2010; Castka and Prajogo, 2013; Naveh and Marcus, 2004; Goh Eng et al., 2006), which for the sake of this research were listed among the dependent variables. Additionally, due to the particular character of the present work, i.e. the interrelation between the ISO 14001 environmental management systems and environmental insurance, some independent variables relevant only to this research area had to be identified.

Based on the above, a catalogue of features and independent variables was divided into three groups: systemic features, awareness-related features and organisational features. The independent variables are presented in Table 2. 


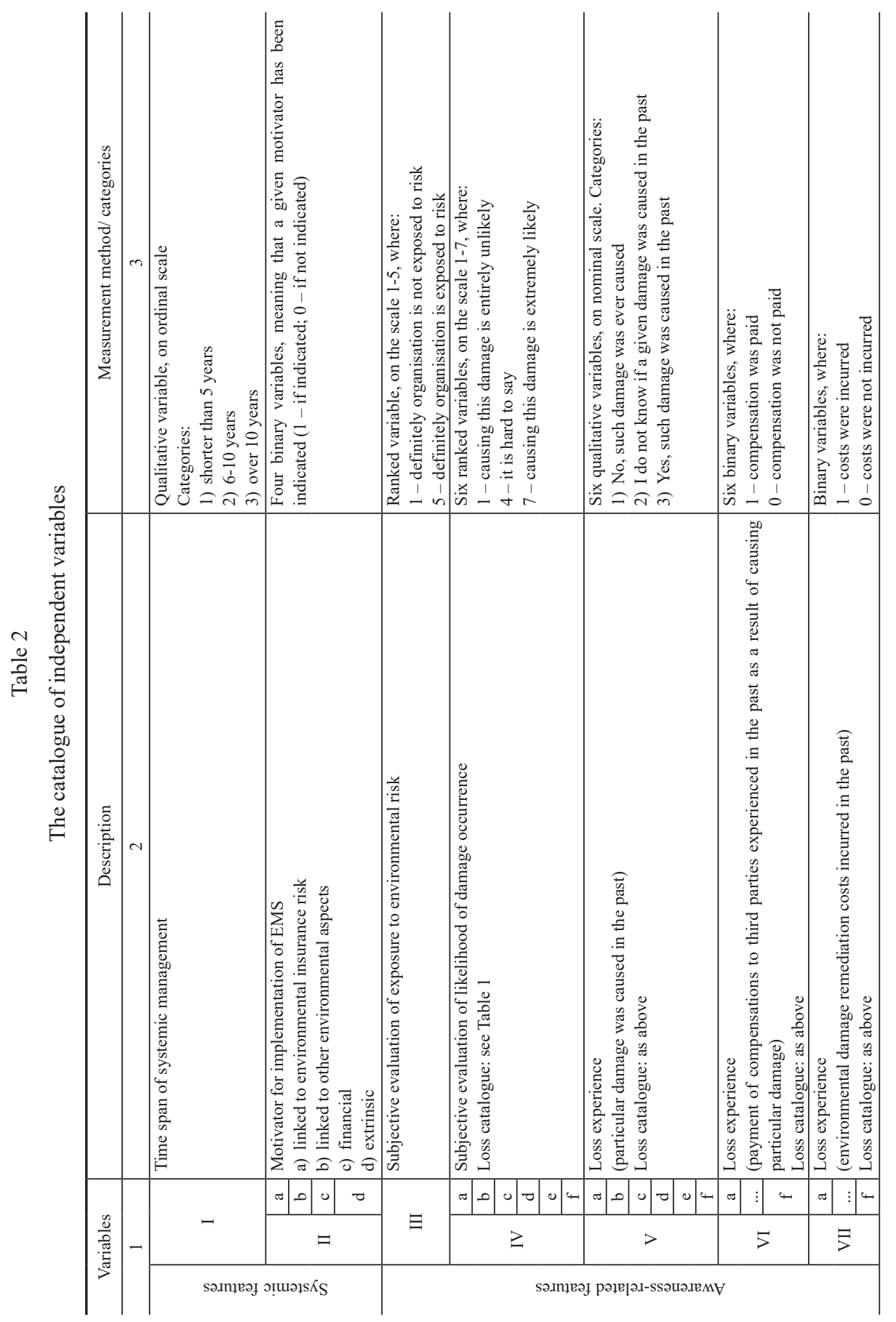




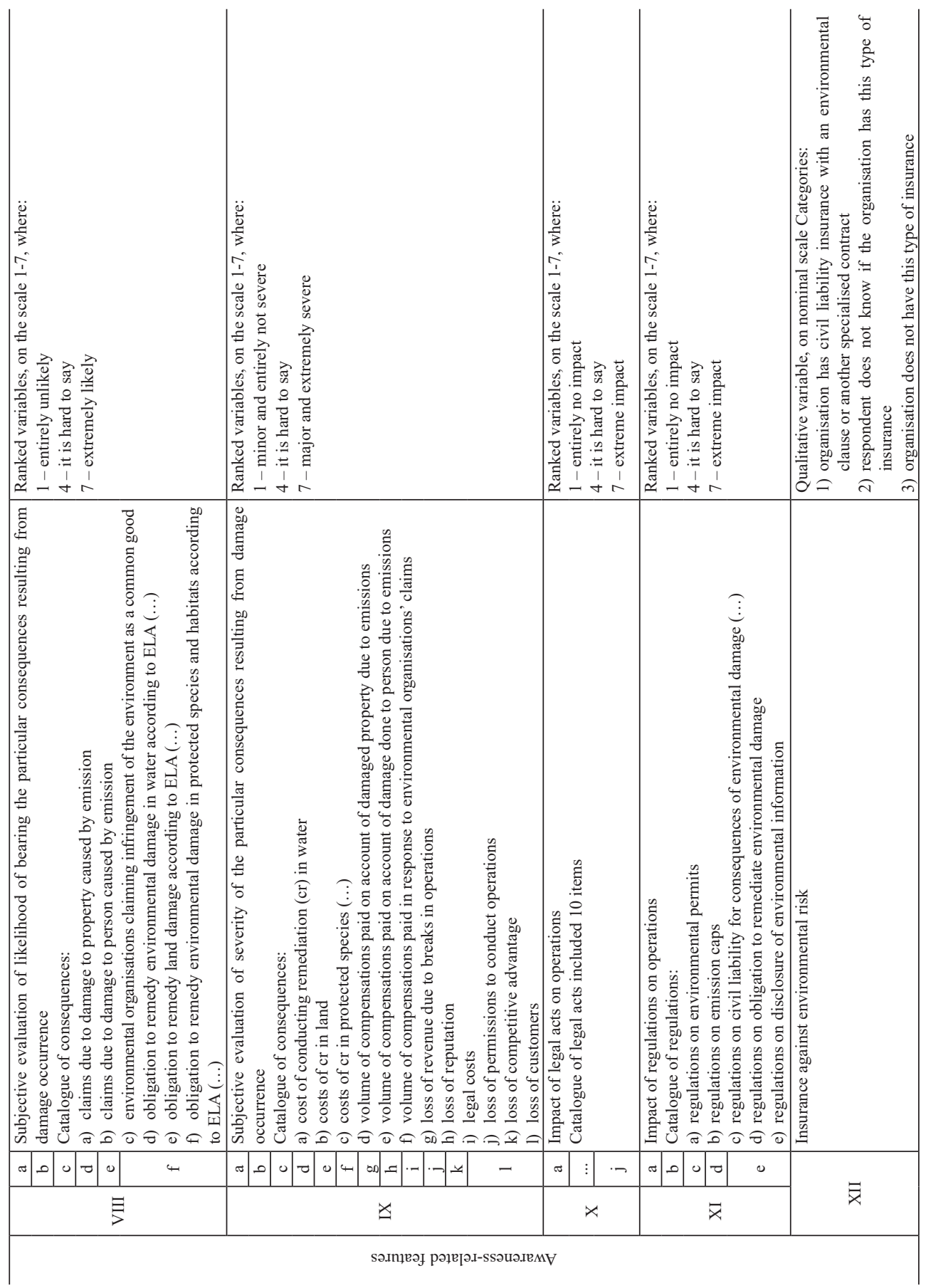




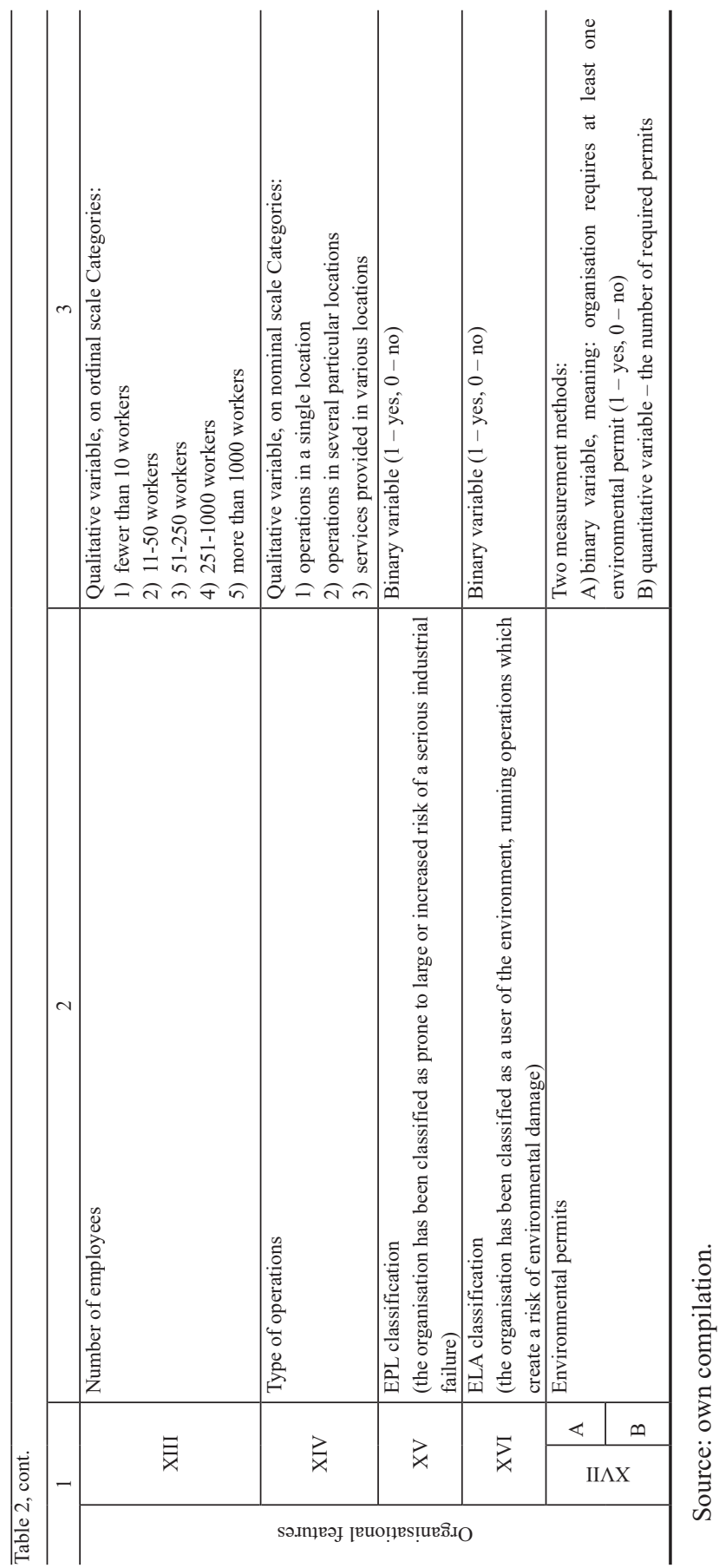


The values of the dependent and independent variables were obtained via an electronic survey conducted between November 2018 and May 2019. The club of Polish Forum ISO 14000 dealt with the technical side of the survey, supported by the recommendation from the Polish Centre for Accreditation. The research was completed in multiple stages; the first phase (NovemberJanuary) encompassed the assembly of the list of organisations which implemented and certified ISO 14001 in Poland. Due to the limited willingness to cooperate, the list is not complete, but 1612 organisations were ultimately invited to participate in the survey. Moreover, the survey contractor conducted a vigorous promotional campaign (during conferences and training courses, e.g. COP 24 in Katowice), and also applied strong motivators to fill in the survey(such as free access to a platform for generating individually tailored registers of legal requirements concerning the environment (www.regulis.pl), and free participation in a specially arranged online training on legal changes in laws on waste management which entered into force at the end of 2018). As a result, the respondents (those responsible for ISO 14001:2015 systemic environmental management in organisations) from 183 companies finished the survey, while 121 of these completed the questionnaire in full.

The final phase of the research comprised statistical analysis of the responses in order to identify the interrelations. At this stage a very crucial fact must be mentioned, namely the statistical features (dependent and independent variables) were of various types, most of which were qualitative features and only few of them quantitative. The qualitative features were either dichotomous or multivariate, some of them measured on ordinal scale, while some on nominal scale. Hence, the type of statistical features became the major criterion of choice for the measurement method and for drawing conclusions about the correlation between them. An additional criterion was the number of observations and distribution of responses (in the case of ranked features). Therefore:

a) when the dependent variable and the independent variable were qualitative, the preferred test was the independence chi-squared test, and the power of this correlation was evaluated by means of the Cramer's V coefficient and contingency coefficient; additionally in the case of the square $2 \times 2$ tables, the Yates correction was used;

b) for independent variables the variants were ranked (e.g. 1 - entirely unlikely, ..., 7 - very likely), the U-Mann-Whitney test was used for dichotomous dependent variables, and the Kruskal-Wallis test if the dependent variable came in more than two variants. This choice was also prompted by a distinct asymmetry of response distribution as well as the fact that it was impossible to conduct an independence chi-squared test because of the too small numbers predicted in some squares of the contingency table (crosstab); 
c) when the dependent variable was a quantitative (e.g. the number of required permits, the number of claims registers kept by a company) or a ranked one (assessment of a propensity from 1 to 5), and the independent variable variants were ranked, the significance of the correlation was concluded on the basis of the Spearman's rank correlation coefficient; this choice was determined by the ranking character of the features and also by the distribution of the responses;

d) whenever drawing conclusions concerning the features' correlation required multiple testing in pairs, the Bonferroni correction was applied.

In all the cases the correlation was considered significant when the $p$-value of a given test did not exceed the statistical significance level of 0.05 .

\section{RESULTS AND DISCUSSION}

\subsection{Part 1 - Attributes of an organisation vs. relevant systemic solutions}

Statistical inference was conducted in turns for each possible pair of "dependent variable - independent variable". The results are presented in the synthesized form of a matrix, in which all the cases have been marked where it is possible to deduce that there is a statistically significant correlation between systemic, organisational or awareness-related variables (independent variables) and the dependent variables which constitute the relevant systemic solutions i.e. variables referring to personal integration, project, information and volume of risk (see Figure 1).

This approach enables an easy identification of the number of existing correlations between the above and distinguishing the areas where correlations are the most or the least frequent.

The analysis of the correlation matrix through the prism of relevant systemic solutions shows that the lowest number of correlations was obtained in the area of personal integration and project-related variables and some selected variables concerning volume of risk: remediation indispensable in order to restore the original condition of the environment in response procedures topotentialemergencysituations; environmentalgoals (establishment); environmental goals (accomplishment). This means that implementation of the aforementioned relevant (from the insurance point of view) systemic solutions is seldom contingent on the systemic, awareness-related or organisational attributes of an entity managed in line with the ISO 14001 standard.

On the other hand, when looking through the viewpoint of the independent variables, it can be stressed that statistically significant relations were most 


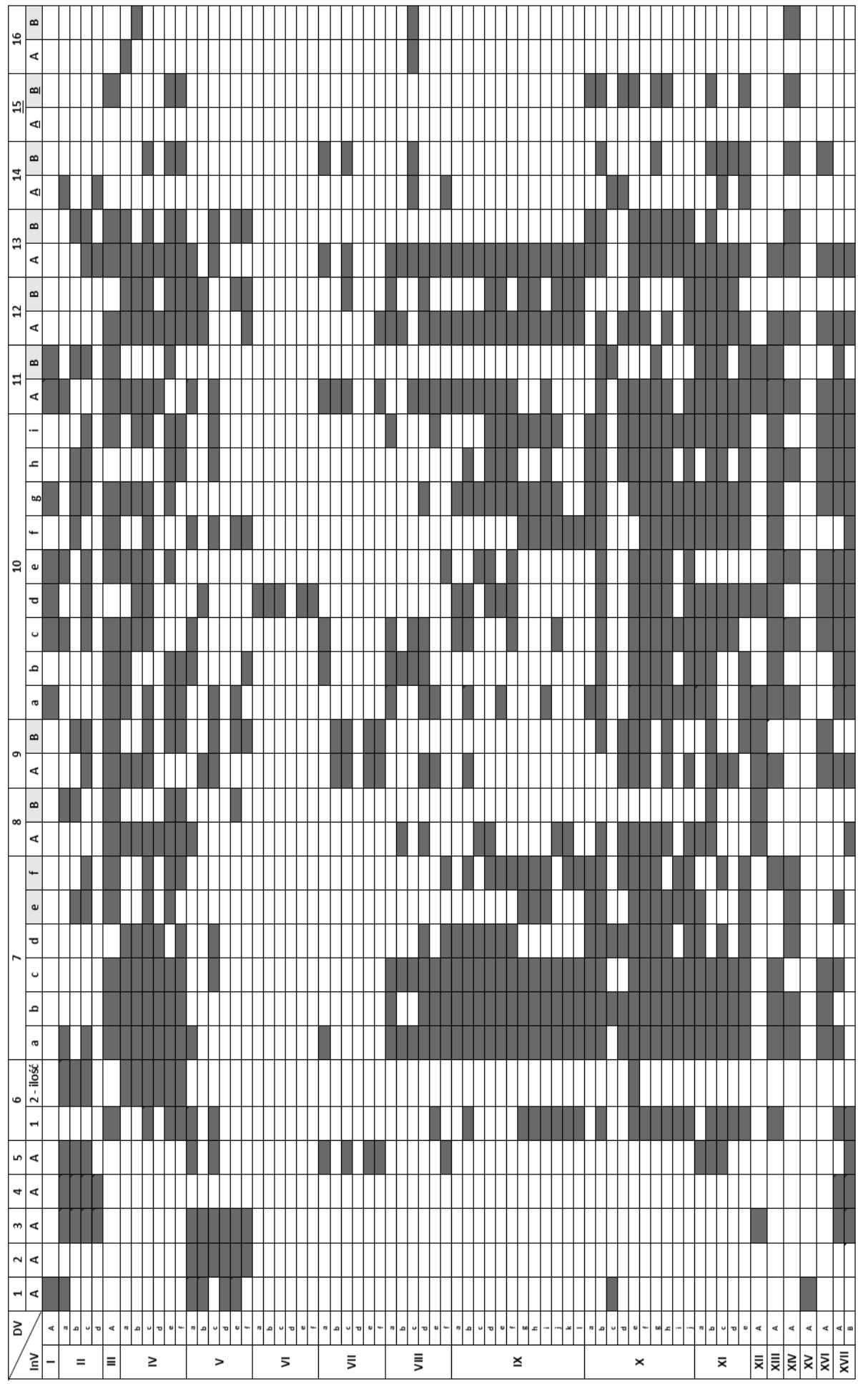

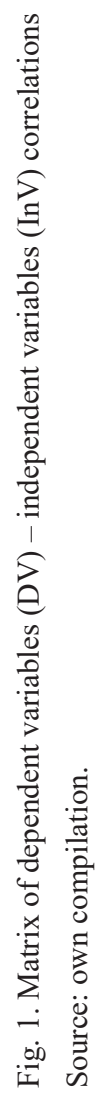


infrequently identified when the independent variable concerned loss experiences (with reference to the payment of compensation to third parties or bearing the environmental remediation costs) or the time span of systemic management variable. In the first case, inference about significant correlations was impossible as there were not enough representatives of organisations which would have experienced the indicated consequences of environmental loss or another adverse environmental impact. The lack of loss experiences results from the still infrequent compensation claims made for indirect environmental losses (damage to person or property) and just a few cases of environmental loss which were subject to the Act on prevention and remediation of environmental damage (ELA, 2007), which expects the culprit to bear the remediation costs.

Time span of systemic management presented a statistically significant correlation with just a few variables, including the first personal integration variable. The analysis of detailed findings makes it possible to identify the following regularity: the longer it is since the organisation implemented the system, the more seldom the respondent (the person responsible for ISO 14001 EMS) is simultaneously in charge of the area of environmental insurance. This might result from the natural growth of the company's size as it reaches market maturity. Yet, in a definite majority of cases $(86.6 \%)$, the person completing the survey was not responsible for environmental insurance cover.

Time span of systemic management was also significantly correlated to the monitoring of environmental aspects variable. Here, the longer the time elapsed since the system implementation, the higher the percentage remained of the entities which regularly monitored environmental aspects (except such aspects as noise emissions, volume of waste ${ }^{5}$, condition of technical means of limiting the adverse environmental impact or installation parameters). Additionally, in organisations which implemented EMS more than a decade ago, preventive actions were more common, and this means that a long period of EMS operating is conducive to enhancement of both its preventive and measurement functions.

In the case of the remaining independent variables, the scope and strength of their correlation with implementation of relevant systemic solutions (from the insurance point of view) remains diverse; what can be more frequently noticed is the correlation in the area of awareness-related variables rather than organisational or systemic ones.

Another systemic variable (following the time span of systemic management), namely the motivators for implementation of EMS shows very

\footnotetext{
${ }^{5}$ The amount of waste was the most frequently monitored aspect in the surveyed organisations.
} 
interesting correlations. Although in this area the number of correlations to RSS implementation is vast, it is fairly difficult to indicate the group of motivators (linked to environmental insurance risk; linked to other environmental aspects; financial or extrinsic ones) which is most essential for the implementation of relevant systemic solutions. However, it has to be stated that insurance-related motivation was far more often (59\% vs. $21 \%$ ) pointed to as one of the reasons for the system implementation if the respondent was in charge of both the EMS and the insurance cover. Parallel to that, regardless of the motivation type, such an indication also meant that the respondent usually knew whether an insurance contract had been signed - for instance, reference to the insurance motivation increased the percentage of the competent respondents from $30 \%$ to $61 \%$. The motivation to implement the EMS was also crucial for response distribution to the question whether the insurance system is treated as the interested party by ISO 14001 EMS. This correlation did not manifest itself in the growth in positive answers (the percentage here was always low, approximately $21 \%$ ), but it did occur in the fluctuations of the numbers which responded "no" or "I don't know"; indication of motivators resulted in a drop in the percentage of respondents who denied having any knowledge about them. Nonetheless, despite the small number of the entities which treated the insurance sector as an interested party within ISO 14001 EMS, the indication of three types of motivation for system implementation was conducive to considering the relevant criteria (from the point of view of insurance) for the selection of the interested parties (the lack of such a relation was only seen in relation to the extrinsic motivator). This means that intrinsic factors, be it environmental or economic, force organisations to take into account the criteria which matter for the volume of environmental insurance risk $^{6}$. The type of motivation for the implementation, on the other hand, did not affect repressive action planned or taken in connection with a likely damage or establishment of environmental goals. In the course of analysis of the results regarding the other RSS, it becomes clear that significant correlations with motivators for implementation of ISO 14001 EMS are often irregular (they do not refer to each motivator type or each type of loss). The most frequent and significant motivator for implementing the system, which affected the distribution of dependent variables, was the financial incentive. Moreover, it is also crucial to state that the group of extrinsic motivators (meeting the insurer's requirements, meeting other co-operators' requirements) is not usually significantly related to any relevant systemic solution. Nevertheless, it

\footnotetext{
${ }^{6}$ These categories are the environmental risks which - considering the current state of the Polish market - can be covered by insurance.
} 
has to be said that indicating motivators connected with environmental insurance risk is significantly related to taking preventive action and planning remediation indispensable in order to restore the original condition of the environment in response procedures to potential emergency situations.

Very few and irregular correlations were observed with regard to organisational variables. The lowest number of correlations with RSS was confirmed for EPL classification variable. This, however, could result from the fact that one of the two available categories of this variable was of a very small size - the vast majority of the studied entities did not belong in the category of companies prone to large or increased risk of a very serious industrial failure (as many as $95.1 \%$ ). This percentage was slightly lower in organisations where the same person is responsible for ISO 14001 EMS and insurance in the area of environmental risk. Hence, companies facing high or increased risk of a major industrial failure are more likely to link the competences regarding environmental insurance and ISO 14001 EMS. Still, it is quite surprising that these companies achieve environmental goals less frequently, especially in group B of loss catalogue ${ }^{7}$ (i.e. the reduction of likelihood of damage occurrence and damage scale referring to a substance emission into the air and the volume of adverse impact caused by energy emission). A relatively higher environmental awareness of the respondents surveyed on behalf of the companies prone to large or increased risk of a very serious industrial failure, might in fact lead to their perception of a greater gap between the expected condition and the actually achieved state while striving to reach the goals.

The implementation of a much larger scope of relevant systemic solutions appeared to be statistically contingent on the organisation's belonging to the group of entities using the environment and running operations which create a risk of environmental damage (subject to a more severe - based on the rule of risk - regime of environmental damage liability), namely ELA classification. Such organisations estimate the likelihood of environmental damage (damage to surface waters, groundwater, land), register claims, monitor the majority of environmental aspects (except emissions of substances into the air, noise emissions or the volume of waste - there are no significant differences in this area between companies which vary in terms of ELA classification), take preventive and repressive action more frequently as well as develop response procedures to potential emergency situations. Surprisingly, there is a correlation between the organisation's category (according to ELA criterion) and planning environmental remediation within the procedures. The

\footnotetext{
See Table 1.
} 
statistically significant positive correlation was only identified in the area of planning for remedying action in connection with group B of loss catalogue, even though the law does not urge entities to take steps with respect to these elements of the environment.

Among the organisational variables, the correlations which attract attention are the ones connected with the number of employees variable. The analysis of response distribution shows clearly that the smallest organisations stand out most notably: they hardly ever estimate the likelihood for group B of loss catalogue, rarely keep any records of claims, almost never monitor any selected environmental aspects and usually do not plan any response procedures to potential emergency situations. In the remaining employment categories there are often no distinct variations in RSS implementation. Yet, one can state that companies with the largest employment figures are more frequently engaged in the estimation of the likelihood of certain damage occurrences, monitoring selected environmental aspects and taking preventive and repressive actions. In the case of preventive measures one can detect an almost monotonic correlation with the volume of employment - its increase leads to the rise in the percentage (from 20\% to $78 \%$ ) of organisations which take such action. Along with the growth in the number of employees, one can see the rise in the number of types of losses for which repressive and preventive activities, the number of claims registers as well as the number of the introduced response procedures to potential emergency situations(referring to group A of the catalogue of losses).

Not many correlations were observed in the area of the type of operations variable. Although, when it comes to some of the RSS (e.g. regular monitoring of environmental aspects, the number of response procedures, the number of types of losses for which remedying action has been anticipated in procedures, the number of types of losses for which preventive actions are taken), the organisations whose business is not carried out in one particular place were doing a much better job of implementing them. This may be linked to a relatively more difficult assessment of the exposure to environmental risk due to various or uncharted locations. Such a situation generates the need for implementing organisational tools to control this risk.

Finally, statistically significant correlations within the area of organisational variables were most often identified between the implementation of RSS and the requirement to obtain at least one environmental permit as well as the number of permits for running the operations (environmental permits variable). These correlations could be seen even in the case of project and personal integration variables, which were rather weakly determined by other independent variables. Hence, in organisations which have at least one 
environmental permit, respondents' desirable competences regarding responsibility and knowledge about environmental insurance are observed more often. In such organisations it is also more common to declare considering the relevant criteria, from the insurance point of view, when it comes to the selection of stakeholders and environmental aspects ${ }^{8}$. Except for the above, some positive correlations were noticed between the variables referring to the permits obtained by the organisation and most of the remaining dependent variables. Permit requirement has no significant effect only on remediation indispensable in order to restore the original condition of the environment in response procedures to potential emergency situations, environmental goals (establishment) and environmental goals (achievement). Hence, it seems that the permit requirement increases the awareness of environmental risk, which results in taking organisational action to control it. The number of permits also matters - as it definitely stimulates the scale and scope of RSS implementation.

The largest range of correlations was observed between the awarenessrelated independent variables and the majority of dependent variables. The exceptions which should be pointed out are the personal integration variables, the project-related variable (treating insurance sector as an interested party) and also the variables referring to the damage scale in the area of environmental goals. First of all, it has to be ascertained that the percentage of organisations which jointly deal with the two areas of environmental risk control (ISO 14001 EMS and environmental insurance) as well as those which identify the insurance sector as the stakeholder is rather low and does not change under the influence of awareness factors or because of the influence of other independent variables. It was only possible to draw conclusions concerning significant correlations with regard to loss experiences (past environmental damage occurrence), although in this case the absence of knowledge about loss experiences was accompanied by lack of joint competences in the area of ISO 14001 EMS and environmental insurance as well as lack of awareness whether the insurance sector is treated as an interested party, or if any insurance contracts have been signed by the company. For instance, while within the group of respondents who knew about the finalised insurance contracts the percentage of people without knowledge of the loss record (depending on the type of loss) accounted for $5.5 \%$ up to $11.4 \%$, in the group of respondents who

\footnotetext{
${ }^{8}$ For the dependent variable insurance sector treated as an interested party, the answer "I don't know" is actually the one responsible for the identified statistically significant correlation. Respondents from the organisations whose operations did not require any environmental permits, more often did not know if the insurance sector was treated by their organisation as an interested party in the context of ISO 14001 EMS.
} 
lacked knowledge about the contracts signed the respective percentage it was between $67.8 \%-69.2 \%$.

Quite contrary and rather baffling evidence emerged from the analysis of the correlation between loss experiences and another personal integration variable: even though most respondents knew who was responsible for the insurance cover, almost half of them denied knowing if any particular types of damage have been caused. Such declared ignorance, albeit infrequent in the scale of the whole study, (regardless of the type of loss, no more than $26 \%$ of the respondents knew anything about the organisation's loss experiences), which may be quite surprising when considering the position of each respondent within their company or may even deem such EMS to be fictitious organisational solutions.

As already been stated, the lack of significant correlations between awareness-related variables and RSS with regard to environmental goals relevant from the point of view of the process of providing insurance (their establishment and the degree of accomplishment) ${ }^{9}$ is also an interesting finding. Additionally, it has to be said that environmental goals which amount to reducing the likelihood or scale of the caused damage are not established very often and the frequency is contingent on the type of loss. Most often, in slightly over $50 \%$ of the organisations, the goals are set in connection with polluting the land, the air or energy emissions, while in other cases of losses the percentage is far lower. On the other hand, one should add that the percentage of organisations for which one of the systemic goals is a reduction in the consumption of natural resources (which, insurance-wise, is not a relevant systemic solution) is as high as $76 \%$. The above is evidence that there exists a form of incompatibility between the approach to environmental risk in ISO 14001 EMS and its perception through the prism of insurance provision.

Another large group of correlations was also identified between awareness variables and informative variables or selected project variables (the criteria for selection of the parties interested and criteria for selection of environmental aspects) and some of the categories referring to the volume of risk variable (taking preventive or repressive action, planning remediation indispensable in order to restore the original condition of the environment in response procedures to potential emergency situations).

\footnotetext{
${ }^{9}$ Very few correlations can be seen solely in the subjective evaluation of the likelihood of damage occurrence and also the effect that legislation and particular regulation categories have on company operations and the establishment of environmental goals in group B of loss catalogue. The goals were established more often if the respondents also perceived the likelihood of damage occurrence as high and assigned greater importance to legal acts and particular regulations for carrying out their operations.
} 
The entities which evaluated higher the likelihood of all loss occurrences in the catalogue (the subjective evaluation of the likelihood of damage occurrence variable) more often implement RSS. A particularly strong correlation can be seen between the subjective evaluation of the likelihood of a particular environmental loss occurrence and implementation in the organisation of the estimation procedure for the likelihood of this loss. Mixed correlations (i.e. for various losses) were weaker, but still significant in group A of loss catalogue (environmental losses). The correlations obviously manifested themselves in the fact that companies which indicated higher probability of particular losses occurrence, significantly more often implemented likelihood estimation procedures. What is more, the findings imply that the higher the evaluation of the damage occurrence likelihood:

- the more often a probable maximum amount is estimated of costs necessary to be incurred in case the loss does occur;

- the more often an environmental claims register is kept (especially for the same type of loss) and the larger number of registers is also kept,

- the more often the environmental aspects of a given type of loss are monitored,

- the more frequently preventive actions are taken in connection with both groups of loss catalogue and the larger is the number of types of losses, for which these actions are taken,

- the more frequently repressive actions are planned or taken in connection with both groups of loss catalogue, the larger the number of types of losses for which these actions are planned or taken,

- the more frequently the response procedures are introduced to potential emergency situations, the larger the number of these procedures developed in the organisation.

The presented regularities (particularly the quantitative ones) are mainly connected with RSS linked to the losses from group A of loss catalogue. One exception to these regularities refers to the evaluation of the likelihood of loss occurrence in protected species and habitats, which had no significant influence upon keeping claims registers or monitoring any environmental aspects at all.

Further analysis demonstrates that the effects of the high evaluation of likelihood of damage occurrence are quite different from what results from high evaluation of likelihood of bearing the particular consequences resulting from damage occurrence (according to the catalogue, see Table 2). In the latter case (evaluation of likelihood of bearing the particular consequences variable),there are much fewer correlations and they usually refer to RSS implementation in the area of group A of loss catalogue. This can probably be justified by the legislator who introduced a severe regime of administrative 
liability for environmental damage of group A of loss catalogue; as an ex lege liability (requiring no third party for the claim to take place), which is often based on the rule of risk, may generate a large expenditure burden for the culprit. At the same time, it must be pointed out that respondents evaluate the likelihood of damage occurrence much higher than they do for the likelihood of bearing the particular consequences. This seems to indicate the need in an organisation implementing the EMS for educational input which can be provided by consultants, auditors or certification entities.

A similar range of correlations was noticed concerning the independent variable: evaluation of severity of the particular consequences resulting from damage occurrence. The higher the evaluation of the gravity of particular consequences (catalogue of consequences, Table 2), the more frequently they estimated the likelihood of environmental damage (primarily in group A of loss catalogue), monitored environmental aspects significant for the volume of environmental risk, took preventive action, planned repressive action or completed it in the past or implemented response procedures to potential emergency situations regarding losses in group A of loss catalogue. A high evaluation of the severity of the consequences, on the other hand, was rather seldom significantly linked to monitoring environmental aspects regarding the informative variable ${ }^{10}$. Conversely, significant dependencies were observed in the area of monitoring the environmental aspects which determine the volume of environmental risk. The higher the evaluation of severity of the consequences of damage occurrence, the more often the condition of technical means of preventive or repressive measures and installations' parameters was monitored ${ }^{11}$.

A particularly large number of statistically significant correlations were identified between implementation of RSS and the independent variables describing the impact of legislation upon organisational activities (both

\footnotetext{
${ }^{10}$ Monitoring the volume of waste is an exception; it takes place more often if a high evaluation is indicated regarding gravity of consequences such as loss of revenue due to breaks in operations, loss of reputation, the necessity to bear the legal costs, loss of permits, loss of competitive edge or loss of customers. There was no statistically significant correlation in the area of other consequences such as payment of compensations or benefits or bearing the costs of remedying the environmental damage. Parallel to that, the volume of waste is the most often monitored environmental aspect. The structure of the above dependencies turns our attention to the way in which EMSs are perceived, which is more often connected with aspects not directly bound to the elements relevant to the development of environmental insurance.

${ }^{11}$ Installation - stationary technical unit or a group of stationary technical units, technologically connected, legally owned by the same entity and located within the premises of one company, buildings which are not technical units or groups of these, the exploitation of which may cause emissions.
} 
particular legal acts - impact of legal acts on operations variable, and regulations from the objective standpoint-impact of regulations on operations variable). The higher the influence of particular legal acts or types of regulations was ranked, the more often RSS were implemented, especially in the area of informative and volume of risk variables (the number of correlations was relatively low only with reference to the variables concerning goals and including environmental remediation within response procedures to potential emergency situations), and also the project variable (a higher ranking of the regulation impact led to the more frequent consideration of relevant criteria from the insurance point of view - for selection of environmental aspects). The number of dependencies was not equal in the case of all the acts/types of regulations. The less stimulating acts for implementation of RSS seem to be the following: Act on maintaining cleanliness and order in municipalities, Act on microorganisms and genetically modified organisms, Act on plant protection and Act on waste. In the last case, though, a very powerful correlation exists between the evaluation of the impact the act has on company operations and taking action aimed at monitoring volume of waste. The strongest role in the determining development of environmental insurance is linked to the act on the prevention and remediation of environmental damage (ELA). It is not surprising, then, that the higher the evaluation of the impact of this act, the greater the frequency and scope of most RSSs implementation (a particularly strong correlation was observed when monitoring the condition of the technical means for limiting the adverse impact on the environment). This observation is not congruent with a definitely smaller number of correlations between the evaluation of the impact of regulations regarding the obligation to remediate environmental damage (legitimised by the aforementioned act) and RSS implementation. This may suggest the slight significance attached to the obligation to remediate environmental damage, which demotivates implementation of systemic solutions important from the insurance point of view ${ }^{12}$. This scant importance is also confirmed by the structure of responses to questions regarding the evaluation of the likelihood and severity of the consequences of environmental damage.

Among the independent variables related to awareness there is also insurance against environmental risk. The fact of owning insurance itself constitutes evidence of a high level of the purchaser's insurance awareness.

\footnotetext{
12 Yet it has to be stressed that in spite of the relatively smaller array of RSS implementations in organisations which indicate high evaluation for the influence of this kind of regulations, the selected RSS - particularly important from the insurance point of view - present a statistically significant correlation.
} 
Moreover, the respondent's knowledge (the person responsible for ISO 14001 EMS in the organisation) which refers to the type of finalised insurance contracts connects insurance awareness to ISO 14001 EMS. A definite minority of respondents declared possession of environmental risk insurance and except for just one case it was civil liability insurance with an environmental clause. In the course of the analyses only few statistically significant correlations were distinguished between possession of insurance against environmental risk and RSS implementation, which suggests that insurers do not really motivate the insureds to implement most RSS. This might result from - what was detected at the first stage of the study - the lack of familiarity with the structure and possibilities of ISO $14001 \mathrm{EMS}$ among the representatives of the insurance sector in Poland. At the same time, a statistically significant dependency was identified in two key areas which are most often regulated in the relation with an insurer. Firstly, insured organisations more often implement preventive actions, which is the expected kind of behaviour due to the preventive function of private insurance and the insurers' regulative role. Secondly, these organisations more often estimate the probable maximum cost which may have to be incurred in case environmental damage has been caused, as one of the crucial values indispensable for the preparation of a well-adapted insurance proposal which meets the buyer's needs. Moreover, these organisations keep significantly more claims registers.

Summing up the findings so far, it may be stated that the higher evaluation of the likelihood of damage occurrence, likelihood and the severity of bearing its particular consequences and ultimately, the higher evaluation of the impact of legal acts or specific types of regulations leads to the more frequent implementation of RSS. A staggering exception to this regularity is the number of dependencies observed within another awareness variable, namely subjective evaluation of the exposure to environmental risk. Organisations whose representatives considered their entity to be susceptible to environmental risk $^{13}$ (the answers being 'definitely yes', 'rather yes') less often pointed to RSS implementation, and the significance of this correlation has been confirmed for most of the dependent variables (except those which were in most cases weakly determined in the personal integration and project area and the variables referring to environmental goals and planning remediation in

${ }^{13}$ In the survey, environmental risk was defined and exemplified as a possible state of affairs, unacceptable to the organisation, which may be caused by the organisation exerting an impact upon the natural environment. The environmental risk may be the need to incur the cost of legal services, costs of damage remediation, compensation and benefit payments to third parties as a result of the organisation's impact on the environment. More on the conceptualisation of the term 'environmental risk' in (Lemkowska, 2020b, pp. 21-27). 
response procedures to potential emergency situations). There are two main conclusions to be drawn from the above. Firstly, the direction of the correlation in the studied dependencies is probably different from the one originally assumed in the research. RSS implementation is perceived by the respondents as the effective physical control of environmental risk, thanks to which they do not feel significantly exposed to its occurrence. Secondly, the respondents do not see environmental risk as equal to the likelihood of the damage occurrence or of bearing the consequences of this damage. This is because a positive relationship has been observed - as mentioned above - between RSS implementation and the level of likelihood evaluation. Hence, despite the relatively high evaluation of the likelihood of the damage occurrence and the likelihood of the organisation's bearing the consequences of causing this damage, due to the awareness of introduction of preventive measures, monitoring and procedures, the respondents declare limited exposure to risk.

\subsection{Part 2 - Attributes of the organisation vs. propensity for implementation of additional elements of EMSs (additional RSS)}

The analysis of propensity for implementation of additional elements of ISO 14001 EMSs declared by the respondents from the studied organisations ("propensity" in short) was carried out in two phases. First, it was determined whether independent variables (and which of them - systemic, awarenessrelated, organisational) show a statistically significant correlation with the declared propensity. At this stage it was assumed that an organisation shows propensity if there is at least one potential advantage which may motivate the company to implement an additional system element. Next, the propensity to implement RSS was evaluated depending on the motivators understood as the potential outcomes of implementation. The motivators included: improvement of the organisation's image, lower charges for using the environment, obtaining tax reliefs, lowering operating costs, lowering insurance premiums, increasing the scope of insurance, and obtaining an insurance premium subsidy. In order to draw conclusions about the influence a given type of the motivator had on propensity, a test of equal proportions was repeatedly carried out(for various pairs of motivators), and additionally Bonferroni's correction was used.

In the catalogue of systemic variables there were no variables identified which would significantly affect propensity, the only interesting observation was made concerning the group which indicated motivators for ISO 14001 EMS implementation as linked to environmental insurance risk, where half of the respondents were willing to implement additional RSS due to four or more 
motivators. Others showed propensity in connection with a much smaller number of motivators.

Few correlations were identified for organisational variables. The only conclusion was that slightly more motivators were indicated in organisations which required at least one permit to conduct operations. At the same time, the largest number of motivators was found convincing by organisations employing from 51 to 1000 workers.

In the group of awareness-related variables, numerous statistically significant dependencies were observed, of various (usually low) strength, in the case of seven variables. Higher ranking likelihood of damage occurrence (in surface waters, protected species and habitats, caused by energy emissions) resulted in larger numbers of declared motivators for implementation of additional RSS, there was also a positive correlation between the number of indicated motivators and evaluation of likelihood of bearing various consequences of damage occurrence (this regularity does not hold true for evaluation of likelihood of the need to remediate the damage done to protected species and habitats). Similarly, the higher the evaluation of the severity of the consequences, the more potential benefits were considered to be motivating to implement additional system elements (this was not the rule only in the case of evaluation regarding the remediation costs for damage caused to land and protected species and habitats). Moreover, for the evaluation of severity of bearing the particular consequences variable some statistically significant and positive dependencies were identified between the declaration itself of the willingness to implement some RSS and severity evaluation (the ranking of severity was higher when the organisation declared propensity to implement additional RSSs. $)^{14}$.

On the basis of the results for the evaluation of legal acts one can assert that the fact itself of whether the propensity exists or not is significantly contingent solely upon the impact assessment of the act on the prevention and remediation of environmental damage (ELA). This does not mean, however, that evaluation of the influence of other acts is irrelevant: for as many as five acts (B, D, E, F, $\mathrm{H})$ a positive correlation was found between the number of indicated motivators and the evaluation of impact of these acts. There was also a similar correlation when it came to the evaluation of the impact of regulations on civil liability and those on environmental information disclosure.

The analysis of the relation between being insured against environmental risk and the general propensity for implementation of additional system elements did not identify a significant correlation. However, when the analysis

\footnotetext{
${ }^{14}$ It referred to points $g$ to 1 in the catalogue of consequences.
} 
was narrowed to insurance motivators, some significant dependencies became visible: the organisations which were insured against environmental risk were significantly more willing to implement additional system elements in return for benefits like lower insurance premium, increased scope of insurance or obtaining a premium subsidy. This means that the requirements put forward by insurers as conditions for more favourable terms of insurance (price and scope of the cover) or other parties' requirements (e.g. the state - if a premium subsidy is to be considered) may be accepted by organisations managed in accordance with ISO 14001 standard, provided that they recognise private insurance as an instrument for managing environmental risk.

One of the aims of the study was also to identify the importance of particular motivators for implementation of RSS. Considering the small number of organisations which recognised private insurance as an instrument for managing environmental risk it is not surprising that most respondents showed much more propensity for the implementation of additional system elements if the motivator was not linked to insurance. The differences between the figures are quite large - for instance, $68.3 \%$ of the respondents declared the propensity if it would enhance their company image, as opposed to $30.8 \%$ declaring it in return for an increase in the scope of insurance.

At the same time, based on the conditional likelihood evaluations, it appeared that if the organisation was prone to implementing an additional element for reasons unrelated to insurance (i.e. enhanced company image, lower charges for using the environment, tax reliefs, lower operating costs), it did not lead directly to recognition of insurance-related benefit as motivating (lower insurance premium, increased scope of insurance, subsidised premium). Hence, the motivators from the first category have no significant influence on the choice of the insurance-related motivators. There are, however, some dependencies within the group of insurance-related motivators, for instance, if an organisation is motivated by benefits related to the scope of insurance, it is also practically always motivated by a lower insurance premium.

The prevailing importance of non-insurance motivators is justified by the small percentage of organisations which are insured against environmental risk. Parallel to that, however, among organisations motivated to implement additional RSS by insurance-related factors, there are also ones which currently do not possess this kind of insurance. It should also be stressed that the most commonly indicated motivator amongst the insurance-related ones was the lower insurance premium - considered as motivating by $42.5 \%$ of the respondents. Therefore one may conclude that the integration of solutions referring to ISO $14001 \mathrm{EMS}$ and the process of insurance provision seems plausible in the future. 


\section{CONCLUSION}

The practical purpose of the study was to identify - based on the correlation analysis - easily discernible, objective attributes of an organisation (i.e. time span of systemic management, number of employees, type of operations, EPL classification, ELA classification, environmental permits), on the basis of which an insurance company might be able to categorise potential insureds according to the likelihood criterion regarding implementation of relevant from the point of view of insurance provision - systemic solutions. Statistical analysis did not prove such an application of the research findings to be possible. Statistically significant correlations between independent variables from the systemic and organisational group and implementation of RSS were few and rather weak. Moreover, the insurance sector representatives who participated in the unstructured group interview on the Bulletin Board platform indicated the exogenous (for ISO 14001 EMS) factors which significantly determine environmental risk, such as geographical location or technologies used. Thus, they considered the attempts to categorise systemically managed organisations on the basis of correlation analysis of the organisation's attributes and relevant systemic solutions to be pointless for this manner of determining the terms of insurance (price and scope).

On the other hand, the research showed a fairly large importance of awareness-related variables (mainly subjective evaluation of the likelihood of an environmental damage occurrence, its consequences and assessment of their severity) for the implementation of relevant systemic solutions. The study also demonstrated that the evaluation of the impact of legal acts and environmental regulations on the organisation is positively correlated with the scope of implementation of system elements which are relevant from the point of view of providing insurance. The research findings led to the conclusion that organisation representatives must perceive the implemented systemic solutions as very effective, because their implementation has contributed to a much lower evaluation of exposure to risk. This, however, may cause the organisations to see ISO 14001 and environmental insurance as each other's substitutes, whereas the evaluation of exposure should be treated as a factor describing residual risk, which environmental insurance is provided for.

In spite of many statistically significant correlations, the study does not allow conclusions to be drawn with respect to the possibility of categorising organisations in terms of a particular scale of RSS implementation. Awarenessrelated variables do not make this categorisation possible because declared subjective evaluations may vary depending on the purpose of the declaration and the respondent's expectations concerning the effect of particular responses. Obviously, an anonymous survey conducted for scientific purposes is much 
more likely to generate opinions which are far more realistic than a questionnaire filled in at the request of an insurance agency, where the respondent may actually expect particular types of responses to be linked to proposed terms of the insurance contract.

The identified importance of the awareness-related variables for implementation of RSS may also suggest a certain direction of recommended alterations in the process of ISO 14001 EMS implementation. Building up legal awareness and risk awareness affects implementation of solutions which will enable the integration of system elements and the process of providing insurance. In the long term, this may actually translate into changed terms of insurance contracts, greater precision in adapting the level of insurance premium to the factual risk profile of the organization and, consequently into limiting the barriers to development of environmental insurance.

The frequently declared respondents' propensity for RSS implementation may signify a high level of absorptiveness in organisations managed in conformity with ISO 14001 standard when it comes to the modification of EMS implementation process. This means that setting the requirements aimed at raising awareness (legal, of risk) which determine RSS implementation as well as direct demands for RSS implementation may be accepted by organisations on condition of being offered particular benefits (e.g. more favourable terms of insurance). Hence, it is advisable to make the effort (by insurance sector, certification entities, the state pursuing the aims of environmental policy), to develop recommendations for implementing ISO 14001 EMS while taking into account the needs generated by the process of insurance provision. Building up insurance awareness should be the main priority of these actions. The research has shown that organisations are much more prone to implement RSS as a response to insurance-related incentives (subsidised premiums, lower premiums, broader scope of insurance) if they already possess some kind of cover against environmental risk. Raising insurance awareness, as one of the determinants of finalising insurance contracts, may create favourable conditions for generating a synergy effect between environmental insurance and ISO 14001 EMS.

Statistical analysis of the relations between organisations' attributes and implementation of relevant (for insurance purposes) systemic solutions is pioneering work. Earlier studies only addressed the relations between the above and either the environmental or economic advantages of the systems' implementation. In a large majority of cases a statistically significant correlation was not found in the areas named, for the sake of this research, organisational and systemic variables, which makes them similar to the conclusions in this article. Yet, earlier studies found the connection between the benefits and declaration of intrinsic motivators for system implementation. 
The findings of presented studies also identified the positive correlations between the above and a few RSS. Importantly, however, in no cases of declaring extrinsic motivators was such a statistically significant relation identified (indeed, neither was a negative one).

The conclusions drawn on the basis of the conducted analyses are congruent with the findings of past studies referring to the relation between environmental insurance and EMS. This relation generates immense potential synergy, and ISO 14001 EMS may (but do not have to) affect the likelihood of damage occurrence and its potential scale. The recommendation made in this article with reference to preparing the rules for implementation of ISO 14001 systems in line with insurers' needs is coherent with earlier research conclusions, which said that without a uniform interpretation of ISO 14001 requirements, the value of the certificate for insurers is rather limited and will not replace individual due diligence of the potential insured. At the same time, the demandrelated barriers to the development of environmental insurance market identified by the European Commission and FERMA are in line with the conclusions above, referring to the direction of ISO 14001 systems which should focus on raising the insurance awareness of the potential insured.

\section{REFERENCES}

Act of 13 April 2007 on the prevention and remediation of environmental damage (consolidated text: Journal of Laws of the Republic of Poland 2019, item 1862), ELA.

Berliner, D., Prakash, A., Signaling Environmental Stewardship in the Shadow of Weak Governance: The Global Diffusion of ISO 14001, Law \& Society Review, 47(2), pp. $345-$ 373, 2013.

Boiral, O., Henri, J. F., Modelling the impact of ISO 14001 on environmental performance: A comparative approach, Journal of Environmental Management, 99, pp. 84-97, 2012.

Castka, P., Prajogo, D., The effect of pressure from secondary stakeholders on the internalization of ISO 14001, Journal of Cleaner Production, 47, pp. 245-252, 2013.

Christmann, P., Taylor, G., Firm self-regulation through international certifiable standards: determinants of symbolic versus substantive implementation, Journal of International Business Studies, 37, pp. 863-878, 2006.

Comoglio, C., Botta, S., The use of indicators and the role of environmental management system for environmental performances improvement: a survey on ISO 14001 certified companies in the automotive sector, Journal of Cleaner Production, 20(1), pp. 92-102, 2012.

Country Profile: Spain, Willis International Alert, June, 2, 2009.

Delmas, M., Montiel, I., The Diffusion of Voluntary International Management Standards: Responsible Care, ISO 900, and ISO 14001 in the Chemistry Industry, Policy Studies Journal, 36(1), pp. 65-93, 2008.

Environmental Liability Directive: FERMA's views on the Multi-Annual Work Programme for 2017-2020. Position Paper, FERMA, Brussels 2017. 
Environmental management systems and environmental impairment liability insurance. Two areas in strained relations or in harmony? Swiss Re, Zurich 1998.

Environmental Protection Law of 27 April 2001 (consolidated text: Journal of Laws of the Republic of Poland 2019, item 1396), EPL.

Financial Incentives from Environmental Management Systems (EMSs), Project Findings from Phase I, U.S. Environmental Protection Agency, Washington 2006.

Financial Provision, Protecting the Environment and the Public Purse. Report no 2016/20, European Union Network for the Implementation and Enforcement of Environmental Law, Brussels 2016.

Fura, B., Improving ISO 14001 Environmental Management Systems, Polish Journal of Environmental Studies, 22(6), pp. 1711-1721, 2013.

Gavronski, I., Paiva, E., Teixeira, R., De Andrade, M.C.F., ISO 14001 certified plants in Brazil - taxonomy and practices, Journal of Cleaner Production, 39, pp. 32-41, 2013.

Goh Eng, A., Suhaiza, Z., Nabsiah, A.W., A study on the impact of environmental management system (EMS) certification towards firms' performance in Malaysia, Management of Environmental Quality, 17(1), pp. 73-93, 2006.

Gomez, A., Rodriguez, M. A., The effect of ISO 14001 certification on toxic emissions: an analysis of industrial facilities in the north of Spain, Journal of Cleaner Production, 19 (9/10), pp. 1091-1095, 2011.

Granly, B. M., Welo, T., EMS and sustainability: experiences with ISO 14001 and Eco-Lighthouse in Norwegian metal processing SMEs, Journal of Cleaner Production, 64, pp. 194-204, 2014.

Hajduk, M., Woźniak, L., System zarządzania środowiskowego wedtug normy ISO 14001 jako stymulator ekoinnowacyjności - oczekiwania i korzyści wewnętrzne przedsiębiorstw [The Environmental Management System ISO 14001 as the Stimulus of Ecoinnovations Expected Internal Benefits and the Final Result] [in:] Kaleta, A., Moszkowicz, K., Woźniak, L. (eds.), Przedsiębiorczość i innowacyjność. Wyzwania wspótczesności [Entrepreneurship and innovation: contemporary challenges], pp. 702-709. Wydawnictwo Akademii Ekonomicznej, Wrocław 2006.

Hajduk-Stelmachowicz, M., Environmental Management System According to ISO 14001 as a Source of Eco-Innovations in Enterprises - the Case of Podkarpackie Voivodeship, International Journal of Economics and Management Engineering, 7(3), pp. 650-655, 2013.

Heras, I., Arana, G., Alternative models for environmental management in SMEs: the case of Ekoskan vs. ISO 14001, Journal of Cleaner Production, 18(8), pp. 726-735, 2010.

Heras-Saizabitoria, I., Dogui, K., Boiral, O., Shedding light on ISO 14001 certifications audits, Journal of Cleaner Production, 51, pp. 88-98, 2013.

Jovanovic, D., Janjiz, V., Motives for, Benefits from and Accounting Support to the ISO 14001 Standard Implementation, Economic Horizons, 20(1), pp. 24-41, 2018.

Lemkowska, M., ISO 14001 Environmental Management Systems Assessment From the Insurers' Point of View: Methodical Approach [in:] Akkucuk, U. (ed.), Handbook of Research on Creating Sustainable Value in the Global Economy, pp. 393-408. IGI Global, Hershey 2020a.

Lemkowska, M., Systemy zarzadzania środowiskowego zgodne z wymaganiami normy ISO 14001 na tle wybranych determinant rozwoju rynku ubezpieczeń środowiskowych [Environmental management systems compliant with ISO 14001 standard on the background of selected determinants of the environmental insurance market development]. Wydawnictwo Adam Marszałek, Toruń 2020b. 
Lemkowska, M., The use of ISO 14001 environmental management systems in the process of the preparation and provision of environmental insurance, Acta Universitatis Lodziensis. Folia Oeconomica, 1(346), pp. 63-83, 2020c.

Low Sui, P., Tan, J. H. K., Integrating ISO 9001 Quality Management System and ISO 14001 Environmental Management System for Contactors, Journal of Construction Engineering \& Management, 131(11), pp. 1241-1244, 2005.

Malmborg, A., Mark-Herbert, C., ISO 14001 Certification in BoP Markets, Greener Management International, 56, pp. 57-73, 2010.

Massoud, M. A., Fayad, R., Kamleh, R., El-Fadel, M., Environmental Management System (ISO 14001) Certification in Developing Countries: Challenges and Implementation Strategies, Environmental Science \& Technology, 44(6), pp. 1884-1887, 2010.

Matuszak-Flejszman, A., Benefits of Environmental Management System in Polish Companies Compliant with ISO 14001, Polish Journal of Environmental Studies, 18(3), pp. 411-419, 2009.

Matuszak-Flejszman, A., Determinanty doskonalenia system zarządzania środowiskowego zgodnego z wymaganiami normy ISO 14001 [Determinants of improving the ISO 14001 environmental management system]. Wydawnictwo Uniwersytetu Ekonomicznego, Poznań 2010.

Matuszak-Flejszman, A., System zarządzania środowiskowego - aktualna sytuacja w Polsce [Environmental management system - the current situation in Poland], Problemy Ocen Środowiskowych, 1(8), 2000.

Minoli, D. M., Bell, J. N. B., Composite insurer consideration and attitudes on environmental management systems concerning public liability policies for pollution risks, Journal of Environmental Assessment Policy and Management, 4(3), pp. 329-347, 2002a.

Minoli, D. M., Bell, J. N. B., Insurer perception of environmental management systems regarding insurance for pollution, Journal of Environmental Assessment Policy and Management, 4(3), pp. 349-366, 2002 b.

Minoli, D. M., Bell, J. N. B., Reinsurers Opinions of Environmental Management Systems Concerning Insurance for Pollution, Journal of Environmental Planning and Management, 46(5), pp. 771-780, 2003.

Multi-annual ELD Work Programme (MAWP) for the period 2017 - 2020: Making the Environmental Liability Directive more fit for purpose, version: 28/02/2017, European Commission, Brussels 2017.

Naudé, M., Quaddus, M. A., Rowe, A., Nowak, M., Adoption of environmental standards in Australia: focus on ISO 14001, International Journal of Sustainable Development \& World Ecology, 18(5), pp. 461-468, 2011.

Naveh, E., Marcus, A. A., When does the ISO 9000 quality assurance standard lead to performance improvement? Assimilation and going beyond, Transactions on Engineering Management, 51, pp. 352-363, 2004.

Neugebauer, F., EMAS and ISO 14001 in the German industry - complements or substitutes, Journal of Cleaner Production, 37, pp. 249-256, 2012.

Perez, O., Amichai-Hamburger, Y., Shterental, T., The Dynamic of Corporate Self-Regulation: ISO 14001, Environmental Commitment, and Organizational Citizenship Behavior, Law \& Society Review, 43(3), pp. 593-630, 2009.

Potoski, M., Prakash, A., Do Voluntary Programs Reduce Pollution? Examining ISO 14001' s Effectiveness across Countries, Policy Studies Journal, 41(2), pp. 273-294, 2013. 
Prajogo, D., Castka, P., Yiu, D., Yeung, A. C .L., Lai, K. H., Environmental Audits and Third Party Certification of Management Practices: Firms' Motives, Audit Orientations, an Satisfaction with Certification, International Journal of Auditing, 20, pp. 202-210, 2016.

Prajogo, D., Tang, A. K. Y., Lai, K., Do firms get what they want from ISO 14001 adoption? An Australian perspective, Journal of Cleaner Production, 33, pp. 117-126, 2012.

Prakash, A., Potoski, M., Global Private Regimes, Domestic Public Law: ISO 14001 and Pollution Reduction, Comparative Political Studies, 47(3), pp. 369-394, 2014.

Prakash, A., Potoski, M., Investing Up: FDI and the Cross-Country Diffusion of ISO 14001 Management Systems, International Studies Quarterly, 51(3), pp. 723-744, 2007.

Psomas, E. L., Fotopoulos, Ch. V., Kafetzopoulos, D. P., Motives, difficulties and benefits in implementing the ISO 14001 Environmental Management System, Management of Environmental Quality. An International Journal, 22(4), pp. 502-521, 2011.

REFIT Evaluation of the Environmental Liability Directive. Commission Staff working document, European Commission, Brussels 2016.

Rodríguez, G., Alegre, F. J., Martínez, G., Evaluation of environmental management resources (ISO 14001) at civil engineering construction worksites: A case study of the community of Madrid, Journal of Environmental Management, 92(7), pp. 1858-1866, 2011.

Santos, G., Rebelo, M., Lopes, N., Alves, M. R., Silva, R., Implementing and certifying ISO 14001 in Portugal: motives, difficulties and benefits after ISO 9001 certification, Total Quality Management, 27(11), pp. 1211-1223, 2016.

Singh, M., Brueckner, M., Padhy, P. K., Insights into the state of ISO 14001 certification in both small and medium enterprises and industry best companies in India: the case of Delhi and Noida, Journal of Cleaner Production, 69, pp. 225-236, 2014.

Sorooshian, S., Qi, L. C., Fei, L. L., Characterization of ISO 14001 implementation, Environmental Quality Management, 27, pp. 97-105, 2018.

Spanish report: Questionnaire on the experience gained in the application of the Directive pursuant to Article 18(1) in conjunction with Annex VI of the ELD, 2014. Available online: https://ec. europa.eu/environment/legal/liability/pdf/eld_ms_reports/ES.pdf (accessed June 6, 2020).

Testa, F., Rizzi, F., Daddi, T., Gusmerotti, N.M., Frey, M., Iraldo, F., EMAS and ISO 14001: the differences in effectively improving environmental performance, Journal of Cleaner Production, 68, pp. 165-173, 2014.

To, W. M., Lee, P. K. C., Diffusion of ISO 14001 environmental management system: global, regional, and country - level analyses, Journal of Cleaner Production, 66, pp. 489-498, 2014.

Živcović, S., Takić, L., Živcović, N., The improvement of environmental performances by applying ISO 14001 standard - a case study, Chemical Industry\& Chemical Engineering Quarterly, 19(4), pp. 541-552, 2013.

Zobel, T., ISO 14001 certification in manufacturing firms: a tool for those in need or an indication of greenness?, Journal of Cleaner Production, 43, pp. 37-44, 2013.

Zutshi, A., Sohal, A., Environmental management system adoption by Australasian organisations: part 1: Reasons, benefits and impediments, Technovation, 24, pp. 335-357, 2004.

Received: July 2020, revised: July 2021

Acknowledgement: This research was undertaken as part of the project: Private insurance and environmental management systems complying with ISO 14001 as tools of environmental risk's management - analysis of relations and was funded by a grant of the National Science Centre, Poland (2016/23/D/HS4/02654). 